\title{
Catalytic wet peroxide oxidation of vanillic acid as a lignin model compound towards the renewable production of dicarboxylic acids
}

\author{
Carlos A. Vega-Aguilar ${ }^{a, b}$, M. Filomena Barreiro ${ }^{b, c}$, Alírio E. Rodrigues ${ }^{a, *}$ \\ a Laboratory of Separation and Reaction Engineering - Laboratory of Catalysis and Materials (LSRE-LCM), \\ Faculdade de Engenharia, Universidade do Porto, Rua Dr. Roberto Frias s/n, 4200-465 Porto, Portugal \\ ${ }^{\mathrm{b}}$ Laboratory of Separation and Reaction Engineering - Laboratory of Catalysis and Materials (LSRE-LCM), \\ Polytechnic Institute of Bragança, Campus Santa Apolónia, 5301-253 Bragança, Portugal \\ c Centro de Investigação de Montanha (CIMO), Instituto Politécnico de Bragança, Campus de Santa Apolónia, \\ 5300-253 Bragança, Portugal
}

\section{A R T I C L E I N F O}

\section{Article history:}

Received 28 January 2020

Received in revised form 1 April

2020

Accepted 8 April 2020

Available online 4 May 2020

Keywords:

Dicarboxylic acids

Titanium silicalite-1

Wet peroxide oxidation

Lignin oxidation

Succinic acid

\begin{abstract}
A B S T R A C T
Lignin can be depolymerised and used as a feedstock to obtain renewable raw-materials, providing a green alternative to fossil counterparts. Among others, $\mathrm{C}_{4}$ dicarboxylic acids (DCA), like succinic, malic, maleic and fumaric acids, which can find applications in pharmaceuticals, food industry, and act as solvents, can be obtained from lignin oxidation. To investigate their formation, the oxidation of vanillic acid (VA), a lignin model compound, was studied under catalytic wet peroxide oxidation (CWPO) conditions, using titanium silicalite1 (TS-1) as the catalyst. The effect of temperature, $\mathrm{pH}$, and reaction time were studied. In a second phase, catalyst modification with transition metal oxides ( $\mathrm{Fe}, \mathrm{Co}, \mathrm{Cu}$ ) was tested. Results showed that oxidation under $\mathrm{pH}=10.5$ gives rise to complete VA conversion with hydroxylated DCA, namely malic ( $15 \mathrm{~mol} \%$ ) and tartaric ( $5 \mathrm{~mol} \%$ ) acids, as the main products. At $\mathrm{pH}=4.0$, the production of succinic acid was improved $(7.4 \mathrm{~mol} \%)$, with VA conversion achieving $78 \%$ after $2.0 \mathrm{~h}$ of reaction. At alkaline $\mathrm{pH}, \mathrm{H}_{2} \mathrm{O}_{2}$ reactivity is higher, leading to $\mathrm{C}_{4}$ DCA degradation to low-molecular weight compounds. Catalyst desilication was observed, pointed out for the convenience of using neutral and acidic $\mathrm{pH}$. In acidic $\mathrm{pH}$, Fe and Cu catalysts enhanced VA conversion, and Fe catalyst was more selective towards succinic acid production.
\end{abstract}

(C) 2020 Institution of Chemical Engineers. Published by Elsevier B.V. All rights reserved.

\section{Introduction}

Lignin is a three-dimensional heterogeneous biopolymer providing plants with properties like rigidity, waterimpermeability, and resistance against microbial attack (Kamm et al., 2008). Lignin structure can be envisaged as based in three monomeric units: $p$-hydroxyphenyl, guaiacyl, and syringyl linked together through ether and C-C bonds cre-

\footnotetext{
* Corresponding author.

E-mail addresses: carlos.vega@fe.up.pt (C.A. Vega-Aguilar), barreiro@ipb.pt (M.F. Barreiro), arodrig@fe.up.pt (A.E. Rodrigues) https://doi.org/10.1016/j.cherd.2020.04.021
}

0263-8762/@ 2020 Institution of Chemical Engineers. Published by Elsevier B.V. All rights reserved. ating a cross-linked polymeric structure (Kamm et al., 2008; Li et al., 2015). A promising route towards renewable chemicals and fuels is lignin depolymerisation. Nevertheless, the lignin complex structure hinders its application, encouraging the quest for innovative and more effective depolymerisation strategies (Xu et al., 2014).

Lignin can be depolymerised by several processes including acid/base catalysed depolymerisation, pyrolysis, hydrotreatment, oxidation, reforming and gasification (Erdocia et al., 2017; Li et al., 2015). Lignin oxidation can cause the cleavage of lignin aromatic rings, and aryl ether bonds, among others, being an interesting way to obtain low-molecular weight chemical compounds (Abdelaziz et al., 2018; Kang et al., 2013; 
Pandey and Kim, 2011). In this context, the most studied oxidants are molecular oxygen, nitrobenzene, metal oxides and hydrogen peroxide $\left(\mathrm{H}_{2} \mathrm{O}_{2}\right)$ (Li et al., 2015; Pandey and Kim, 2011). Among them, oxidation with $\mathrm{H}_{2} \mathrm{O}_{2}$ is a highly promising strategy, especially in the presence of catalysts, enabling mild reaction conditions and shorter reaction times (Cheng et al., 2017). Hydrogen peroxide is more reactive than oxygen, even at alkaline or acidic conditions, with the benefit of being considered an environmentally benign chemical (Ma et al., 2015; Pandey and Kim, 2011).

Currently, dicarboxylic acids (DCA) are produced from petrochemical routes or edible biomass fermentation, and find uses in the pharmaceutical industry, polymer synthesis, as a food additive, or used as chemical precursors of other compounds (Höfer, 2015). In the actual context of biomass valorisation, $\mathrm{C}_{4}$-DCA, which include succinic, fumaric, maleic and malic acids, were listed among the 12 building blocks to be produced via this synthetic route (Werpy and Petersen, 2004).

DCA are among the products that can be obtained from lignin catalytic wet peroxide oxidation (CWPO), after cleavage of the aromatic ring. The product selectivity depends on the oxidising agent, catalyst type, process conditions and reactor type (Kang et al., 2013; Ma et al., 2015). In the context of DCA from lignin, several studies have been carried out using wet peroxide oxidation, with and without catalyst (Cronin et al., 2017; Hasegawa et al., 2011; Kang et al., 2019; Ma et al., 2015; Su et al., 2014; Yin et al., 2015; Zeng et al., 2015). However, many of the lignin oxidation processes, including the catalysed ones, are not selective enough to favour the production of a specific DCA, generating a mixture of DCA, introducing the need of additional steps of separation and purification.

Titanium silicalite-1 (TS-1) catalyst, a synthetic zeolite with a MFI framework structure, currently used in the chemical industry, has shown good catalytic activity for oxidation reactions using $\mathrm{H}_{2} \mathrm{O}_{2}$ (Přech, 2018). The increased $\mathrm{H}_{2} \mathrm{O}_{2}$ reactivity is related to several TS-1 characteristics, including microporosity, hydrophobic nature, and the presence of titanium atoms, which reduces the electron density of the O-O bonds, making the oxidant more susceptible to nucleophilic attack (Clerici, 2015; Přech, 2018). TS-1 catalyst has been already tested in guaiacol peroxide oxidation under mild alkaline conditions, producing different DCA, mainly maleic, malic and oxalic acids (Su et al., 2014). These results pointed out the interest to proceed with the testing of TS-1 with other lignin model compounds, namely with the ones with higher complexity.

Catalyst modification with transition metals ( $\mathrm{Fe}, \mathrm{Mn}, \mathrm{Co}$, $\mathrm{Cu}, \mathrm{Ni}$ ) is reported as a strategy to enhance the oxidation activity by increasing hydroxyl radical's formation (Schutyser et al., 2018; Védrine, 2017). Comparatively with precious metals (Pd, $\mathrm{Au})$, transition metals have lower prices, provide easy reaction conditions, and promising results for lignin depolymerisation (Zeng et al., 2015). Transition metals can be used both as homogeneous and heterogeneous catalysts, constituting an interesting strategy to modify the TS-1 catalyst.

The objective of the present work was to study the oxidation of vanillic acid (VA) to produce $\mathrm{C}_{4}$-DCA, using $\mathrm{H}_{2} \mathrm{O}_{2}$ as the oxidising agent in the presence of TS- 1 catalyst. Comparatively with other lignin model compounds found in previous oxidation studies with TS-1, VA shares a similar aromatic structure to guaiacyl, which is the most common structural unit in softwood lignins, and can represent the behaviour of the aromatic ring-opening reactions towards the production of $\mathrm{C}_{4}$-DCA. VA can also be found as a product of lignin oxidation with $\mathrm{O}_{2}$, which is an important process to achieve aromatic compounds (Rodrigues et al., 2018). In a second phase of the work, TS1 catalyst was modified with transition metals (Fe, Co, $\mathrm{Cu}$ ) and tested in the oxidation reaction. The effect of $\mathrm{pH}$ and reaction time on maleic, fumaric, tartaric, succinic and malic acids production yield was studied. Moreover, the occurrence of degradation products was checked.

\section{Materials and methods}

\subsection{Materials}

Vanillic acid (97\%), DL-malic acid ( $\geq 99.0 \%)$, fumaric acid $(\geq 99.0 \%)$, maleic acid (>99\%), succinic acid ( $\geq 99.0 \%)$, L-(+)tartaric acid $(\geq 99.5 \%)$, malonic acid $(>99 \%)$, oxalic acid dihydrate $(\geq 99.0 \%)$, lactic acid solution (85\%, p.a.), $\mathrm{FeCl}_{3} \cdot 6 \mathrm{H}_{2} \mathrm{O}(97 \%)$ and $\mathrm{Co}\left(\mathrm{NO}_{3}\right)_{2} \cdot 6 \mathrm{H}_{2} \mathrm{O}(99 \%)$ were purchased from Sigma-Aldrich Co. LLC. Other reagents were purchased from different suppliers: formic acid (Chem-labs, >99\%), acetonitrile (VWR, HPLC grade), sulfuric acid (Chem-labs, 95-97\%), sodium hydroxide (Merck, p.a.), hydrogen peroxide solution (Fluka, >30\% p.a.), $\mathrm{Cu}\left(\mathrm{NO}_{3}\right)_{2} \cdot 3 \mathrm{H}_{2} \mathrm{O}$ (Merck, p.a.). Catalyst TS-1 was bought to ACS Materials, LLC. All reactants were used as received without further purification.

\subsection{Oxidation procedure}

VA was oxidised using closed steel reactors $(20 \mathrm{~mL})$ comprising an inner PTFE vial, where $5.00 \mathrm{~mL}$ of a $10.0 \mathrm{~g} / \mathrm{L}$ vanillic acid solution, $0.500 \mathrm{~mL}$ of a $30 \mathrm{wt} \% \mathrm{H}_{2} \mathrm{O}_{2}$ solution and $5.0 \mathrm{mg}$ of TS-1 catalyst were placed (10 wt\%, VA-basis). The added oxidant amount was estimated based on oxygen stoichiometric demand for complete VA oxidation to $\mathrm{CO}_{2}$ and $\mathrm{H}_{2} \mathrm{O}$. After adding all reactants and catalyst, $\mathrm{pH}$ was adjusted to the desired value using $\mathrm{NaOH} 2.0 \mathrm{~mol} / \mathrm{L}$ or $\mathrm{H}_{2} \mathrm{SO}_{4} 2.0 \mathrm{~mol} / \mathrm{L}$, for the alkaline and acid medium, respectively. The reactors were then closed and heated to $145 \pm 1^{\circ} \mathrm{C}$, using a heating plate equipped with a thermocouple, and the mixture kept under stirring $(600 \mathrm{rpm})$, for the required reaction time. After the desired reaction time, the reactors were quenched in an ice water bath and samples recovered for analysis. The effect of $\mathrm{pH}(4.0-12.0)$ and reaction time (0-6 h) on selected DCA was studied. Moreover, the formation of DCA degradation products was checked. Experiments were done in triplicate, except when indicated. The $20 \mathrm{~mL}$-reactor was used as a first step to study the process. By using this low-volume system, it was possible to accurately control the reaction conditions, especially temperature. A $145^{\circ} \mathrm{C}$ temperature was chosen after validating the dependence of temperature against $\mathrm{C}_{4}$-DCA yield and VA conversion.

The conducted experiments covered a $\mathrm{pH}$ range where several lignins are soluble in aqueous solution, avoiding mass transfer problems. Moreover, the catalyst does not act in the lignin structure, but in the $\mathrm{H}_{2} \mathrm{O}_{2} \mathrm{O}-\mathrm{O}$ bond, to form hydroxyl radicals. These radicals are soluble in aqueous solution and are responsible for the ring-opening reaction.

\subsection{Quantification of VA, $C_{4}-D C A$}

Quantification of VA, DCAs (maleic, fumaric, tartaric, succinic and malic acids), and degradation products (malonic, oxalic, formic, acetic and lactic acids) was done by highperformance liquid chromatography (HPLC). The apparatus was a Shimadzu UFLC equipped with a Diode Array Detec- 
tor $(210,260 \mathrm{~nm})$ and a Phenomenex ${ }^{\circledR}$ Rezex $^{\text {TM }}$ ROA H $\mathrm{H}^{+}$ column $(300 \mathrm{~mm} \times 7.8 \mathrm{~mm})$ conditioned at $50^{\circ} \mathrm{C}$. The solvent programming (flowrate of $0.5 \mathrm{~mL} / \mathrm{min}$ ) was as follows: 0.0-10.0 $\mathrm{min}_{2} \mathrm{SO}_{4} 4 \mathrm{mmol} / \mathrm{L} ; 20.0-42.5 \mathrm{~min}: 15 \%$ acetonitrile in $\mathrm{H}_{2} \mathrm{SO}_{4} 4 \mathrm{mmol} / \mathrm{L} ; 47.5-100.0 \mathrm{~min}: \mathrm{H}_{2} \mathrm{SO}_{4} 4 \mathrm{mmol} / \mathrm{L}$. For injection (injection volume $20 \mu \mathrm{L}$ ), samples from the oxidation reaction were acidified with $\mathrm{H}_{2} \mathrm{SO}_{4} 2 \mathrm{~mol} / \mathrm{L}$ to $\mathrm{pH} \sim 2$, diluted as needed and filtered through a $0.22 \mu \mathrm{m}$ pore-size filter. The target DCA, degradation products, and VA were quantified using calibration curves prepared from available commercial standards.

Gel permeation chromatography (GPC) analysis was used to evaluate molecular weight changes due to the used oxidation procedures with the modified catalysts. Calibration was done using polystyrene (PS) standards. More details about the applied method can be found elsewhere (Costa et al., 2018), and the HPLC equipment corresponds to the one mentioned above.

\subsection{Carboxylic acids yield and VA conversion}

The information obtained in HPLC quantification was used to determine the individual carboxylic acid $\left(\mathrm{CA}_{\mathrm{i}}\right)$ yields (Eq. (1)), and VA conversion (Eq. (2)). Total $\mathrm{C}_{4}$-DCA yield was obtained as the sum of the individual $\mathrm{C}_{4}$-DCA yields (succinic, fumaric, maleic, malic and tartaric).

VA conversion $(\mathrm{mol} \%)=\frac{[\mathrm{VA}]_{\mathrm{O}}-[\mathrm{VA}]_{\mathrm{f}}}{[\mathrm{VA}]_{\mathrm{O}}} \times 100$

where $[\mathrm{VA}]_{0}$ is the initial VA concentration, and $[\mathrm{VA}]_{\mathrm{f}}$ is the VA final concentration.

$\mathrm{CA}_{\mathrm{i}}$ Yield $(\mathrm{mol} \%)=\frac{\left[\mathrm{CA}_{\mathrm{i}}\right]_{\mathrm{f}}}{[\mathrm{VA}]_{\mathrm{O}}} \times 100$

where $\left[\mathrm{CA}_{\mathrm{i}}\right]_{\mathrm{f}}$ is the molar concentration of the individual $\mathrm{C}_{4}$ DCA $\left(\mathrm{CA}_{\mathrm{i}}=\right.$ maleic, fumaric, tartaric, succinic or malic acid) or degradation product $\left(\mathrm{CA}_{\mathrm{i}}=\right.$ malonic, oxalic, formic or lactic acids).

VA conversion and DCA yield were expressed as average \pm standard deviation

\subsection{Catalyst modification procedure}

Catalyst modification with transition metals ( $\mathrm{Fe}, \mathrm{Cu}$, and $\mathrm{Co}$ ) was done using a modified wet impregnation method according to the methodology described elsewhere (Prasetyoko et al., 2010). Briefly, the TS-1 catalyst was placed in a solution containing a sufficient amount of the cation salt $\left(\mathrm{FeCl}_{3} \cdot 6 \mathrm{H}_{2} \mathrm{O}\right.$, $\left.\mathrm{Cu}\left(\mathrm{NO}_{3}\right)_{2} \cdot 3 \mathrm{H}_{2} \mathrm{O}, \mathrm{Co}\left(\mathrm{NO}_{3}\right)_{2} \cdot 6 \mathrm{H}_{2} \mathrm{O}\right)$, to yield materials with a loading of $2 \mathrm{wt} \%$ of the corresponding oxide $\left(\mathrm{Fe}_{2} \mathrm{O}_{3}, \mathrm{CuO}\right.$, and $\mathrm{CoO}$, respectively). The suspension was heated at $80^{\circ} \mathrm{C}$ for $3 \mathrm{~h}$ under stirring, followed by water evaporation overnight at $100^{\circ} \mathrm{C}$. After that, the obtained product was calcined at $550^{\circ} \mathrm{C}$ for $3 \mathrm{~h}$ to obtain the modified catalyst.

\subsection{Catalyst characterisation}

Modified catalysts were analysed by Scanning Electron Microscopy (SEM), Energy-dispersive X-ray Spectroscopy (EDS) and Electron Backscattered Diffraction analysis (XRD), after being produced and applied in the oxidation process. The catalysts used in the oxidation process were washed with hot water, and dried at $80^{\circ} \mathrm{C}$ overnight, before characterisation.

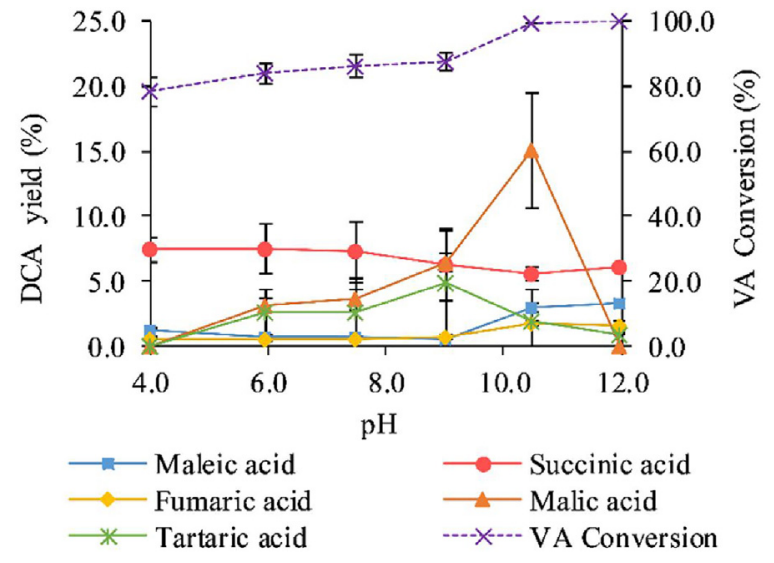

Fig. 1 - Effect of $\mathrm{pH}$ in $\mathrm{C}_{4}$ dicarboxylic acids (DCA) yield and vanillic acid (VA) conversion, with TS-1 $\left(145^{\circ} \mathrm{C}, 2.0 \mathrm{~h}\right)$.

SEM and EDS were performed using a High Resolution (Schottky) Environmental Scanning Microscope with X-Ray Microanalysis and Electron Backscattered Diffraction analysis (Quanta 400 FEG ESEM/EDAX Genesis X4M). EDS was done at high vacuum, $15 \mathrm{keV}, 10 \mathrm{~mm}$ working distance, and a $50 \mathrm{Lsec}$ collection time. For that, samples were coated with Au/Pd by sputtering using the SPI Module Sputter Coater equipment (15 mA, $80 \mathrm{~s})$.

XRD was done in a diffractometer PANalytical EMPYREAN, using $\mathrm{CuK} \alpha 1,2(1.5406 \AA)$ radiation. Diffraction patterns were collected over a range of $4^{\circ}<2 \Theta<70^{\circ}$, using a $0.5^{\circ}$ diverging and antidiverging slits, 0.04 rad Soller slits (receiving and scattering), step size of $0.0167^{\circ}$ and a $30 \mathrm{~min}$ total time. The X-ray tube worked at $45 \mathrm{kV}$ and $40 \mathrm{~mA}$. Crystallinity percentages were calculated based on peak intensity at $2 \Theta=23.04^{\circ}$. TS- 1 non-modified catalyst was given a $100 \%$ crystallinity.

In addition to morphological characterisations, atomic absorption (AA) was used to check leaching of the transition metals from the modified catalysts. For that, the samples were centrifuged and digested using $10 \%$ of concentrated $\mathrm{HNO}_{3}$. The analysis was done using a GBC 932plus equipment, following the Flame Methods Manual for Atomic Absorption by GBC Scientific Equipment PTY Ltd.

\section{Results and discussion}

\subsection{Oxidation with TS-1 catalyst}

\subsubsection{Effect of temperature and $\mathrm{pH}$ conditions}

Concerning $\mathrm{pH}$ conditions, the studied range was 4.0-12.0 at $145^{\circ} \mathrm{C}$, during $2 \mathrm{~h}$, following preliminary results pointed out the higher DCA yield at this temperature. The production yield of $\mathrm{C}_{4}$-DCA (maleic, fumaric, tartaric, succinic and malic acids), as well as the VA conversion, are registered in Fig. 1. The highest reactivity was achieved for basic pHs, with complete VA conversion over $\mathrm{pH}$ 10.5. At acidic medium, a full VA conversion was not reached for the tested time. When $\mathrm{pH}$ increased, the stronger oxidation level leads to the rupture of the aromatic ring, and its conversion to hydroxylated DCAs, like malic and tartaric acids. In pH 4.0, no hydroxylated acids were obtained, and VA conversion was lower.

No catalyst was recovered after the reaction at $\mathrm{pH}$ of 12 indicating that very high $\mathrm{pHs}$ are not recommended to be used with TS-1 catalysts.

Considering temperature, VA conversion increased with temperature increase; behaviour validated using a temper- 

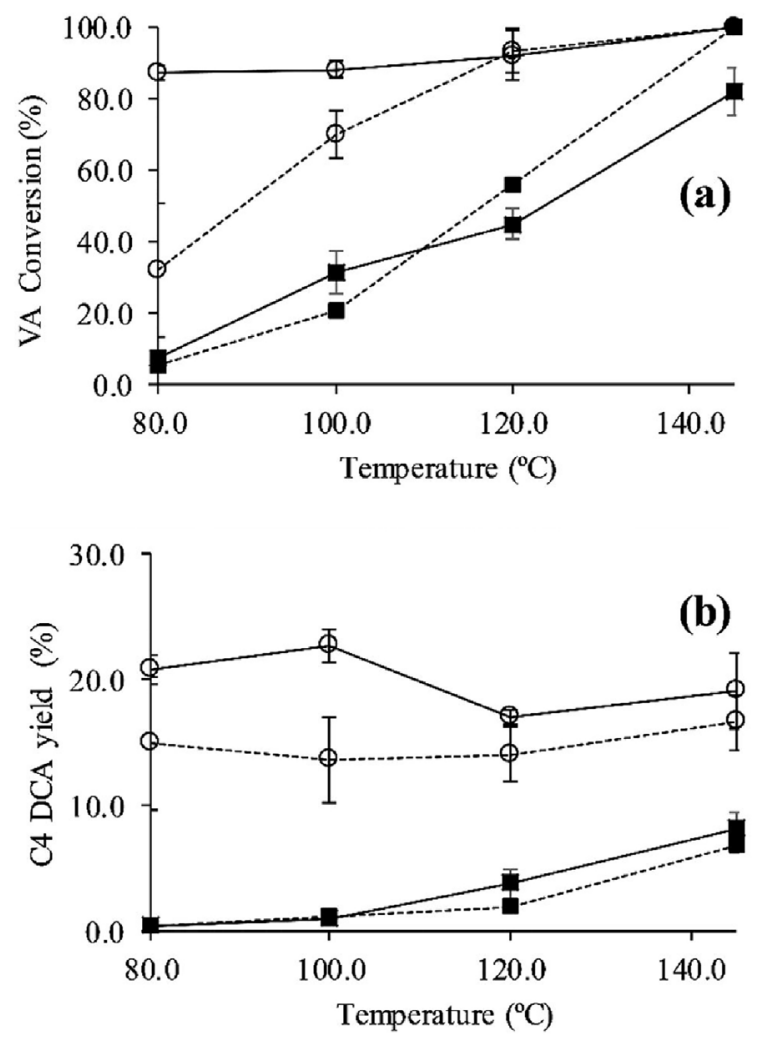

Fig. 2 - (a) Vanillic acid (VA) and (b) $\mathrm{C}_{4}$-DCA conversion at pH $10.5(O)$ and pH $4.0(\square)$, for catalysed $(-)$ and non-catalyzed $(-)$ oxidations ( $3.0 \mathrm{~h}$, by duplicate).

ature range of $80-145^{\circ} \mathrm{C}$ (Fig. 2). Moreover, catalysed and non-catalysed reactions were compared at $\mathrm{pH}$ conditions of 10.5 and 4.0, confirming that the use of TS- 1 catalyst improved conversion, especially under alkaline conditions at lower temperatures. VA conversion for the non-catalysed reaction rise with temperature increase, starting from $32 \%$ at $80^{\circ} \mathrm{C}$ to full conversion at $145^{\circ} \mathrm{C}$. The catalysed reaction gives rise to higher conversion at lower temperatures $\left(80^{\circ} \mathrm{C}\right.$ and $\left.100^{\circ} \mathrm{C}\right)$. At higher temperatures $\left(120^{\circ} \mathrm{C}\right.$ and $\left.145^{\circ} \mathrm{C}\right)$, there is no difference between catalysed and non-catalysed reactions for alkaline $\mathrm{pH}$, while for acidic $\mathrm{pH}$ the non-catalysed reaction led to better VA conversion. Also, for the non-catalysed reactions, a final solution with intense dark colour, together with the presence of sediments, resulting from the condensation of different compounds, was observed. This observation indicates that VA was oxidised to quinones, molecules with high colour intensity, corresponding to the first stage described in Fig. 3. These oxidised structures reacted with each other to produce condensation products, instead of promoting ringopening reactions to form DCAs. As seen in Fig. $2 b$, in all cases, $\mathrm{C}_{4}$-DCA production was higher for the catalysed reaction, in comparison with the non-catalysed one.

The higher reactivity of the catalysed reaction was due to the improvement in the $\mathrm{H}_{2} \mathrm{O}_{2}$ nucleophilic attack capability. This effect is achieved when $\mathrm{H}_{2} \mathrm{O}_{2}$ is adsorbed on catalyst's tetrahedral Ti active sites, forming Ti-OOH species and increasing the partial negative charges of the oxygen atoms (Xia et al., 2017). The microporosity and the hydrophobic nature of the pores are also important factors, enhancing $\mathrm{Ti}-\mathrm{OOH}$ formation, avoiding solvation of $\mathrm{Ti}$ atoms and active species (Clerici, 2015).

Hydrogen peroxide reactivity depends on $\mathrm{pH}$ since it can act as a nucleophile or electrophile species (Xiang and
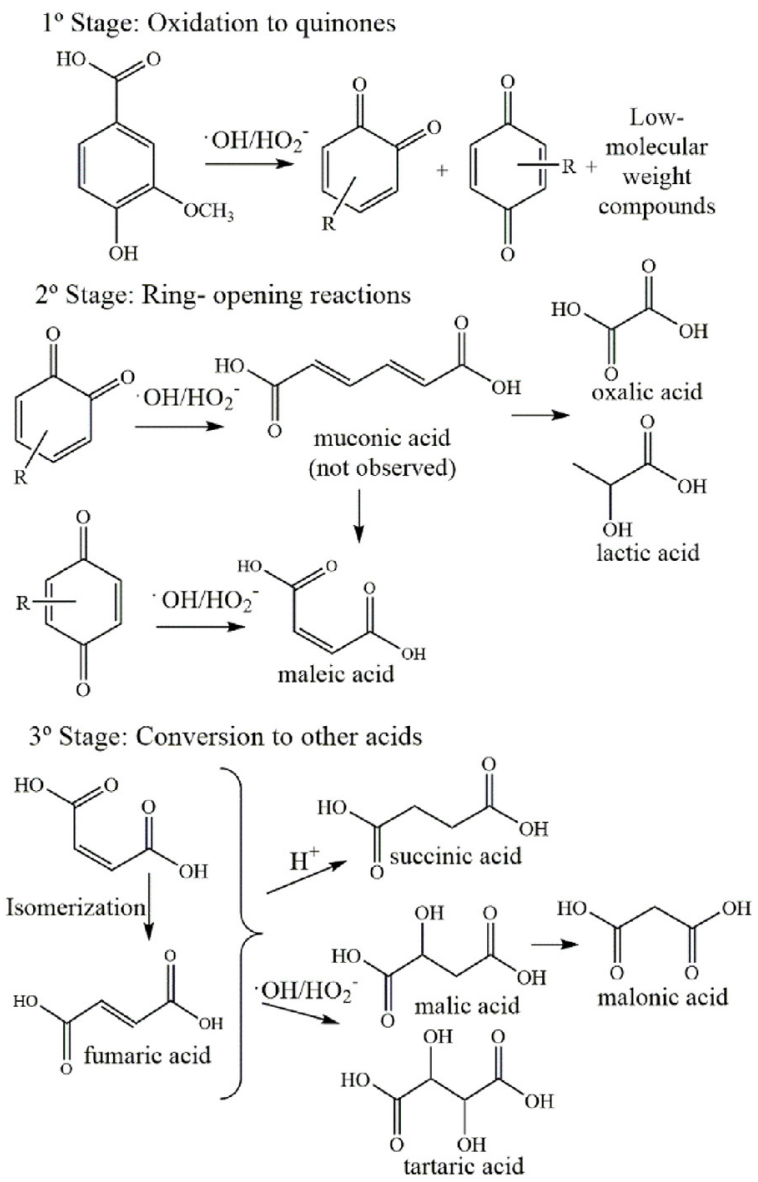

Fig. 3 - Steps for vanillic acid oxidation.

(Modified with permission from Cronin et al. (2017) Copyright 2017. American Chemical Society).

Lee, 2000). In wet peroxide oxidation, the active species for compound's oxidation are hydroxyl radicals $\left(\mathrm{HO}^{\circ}\right)$, and hydroperoxyl anions $\left(\mathrm{HOO}^{-}\right)$. These compounds can later degrade to molecular oxygen, decreasing their reactivity (Yin et al., 2015). Hydrogen peroxide can decompose during oxidation reactions; it is stable in acidic conditions, but quickly decomposes to $\mathrm{H}_{2} \mathrm{O}, \mathrm{O}_{2}$ and $\mathrm{OH}^{-}$above $\mathrm{pH}=6.0$ (maximum decomposition occurs at its $p K_{a}$ ). Moreover, it is sensitive to temperature and the presence of transition metal ions (Xiang and Lee, 2000). Phenolic units are stable to alkaline peroxide but become reactive against hydroxyl radicals derived from $\mathrm{H}_{2} \mathrm{O}_{2}$ decomposition (Sun et al., 1999). Molecular $\mathrm{O}_{2}$ was not studied in this work as an oxidant agent due to its low reactivity compared to $\mathrm{H}_{2} \mathrm{O}_{2}$, avoiding the ring-opening reactions to obtain DCA.

\subsubsection{Effect of reaction time in $C_{4}$-DCA production under} alkaline and acidic conditions

Given the results of the previous section, pH 4.0 and pH 10.5 were chosen for acidic and alkaline conditions, respectively, together with the temperature of $145^{\circ} \mathrm{C}$, to study the production of $\mathrm{C}_{4}$-DCA from VA. For alkaline conditions, complete VA conversion was achieved in less than $30 \mathrm{~min}$, and $\mathrm{C}_{4}$-DCA production reached the highest yield at $2 \mathrm{~h}$, being malic acid the one presented at higher amount (Fig. 4a). However, after $3 \mathrm{~h}$, the yield of malic, fumaric, maleic and succinic acids decreased, which suggested that these DCA were degraded to low-molecular weight compounds. Tartaric acid concentration remained almost constant after a time frame of $2.5 \mathrm{~h}$. 

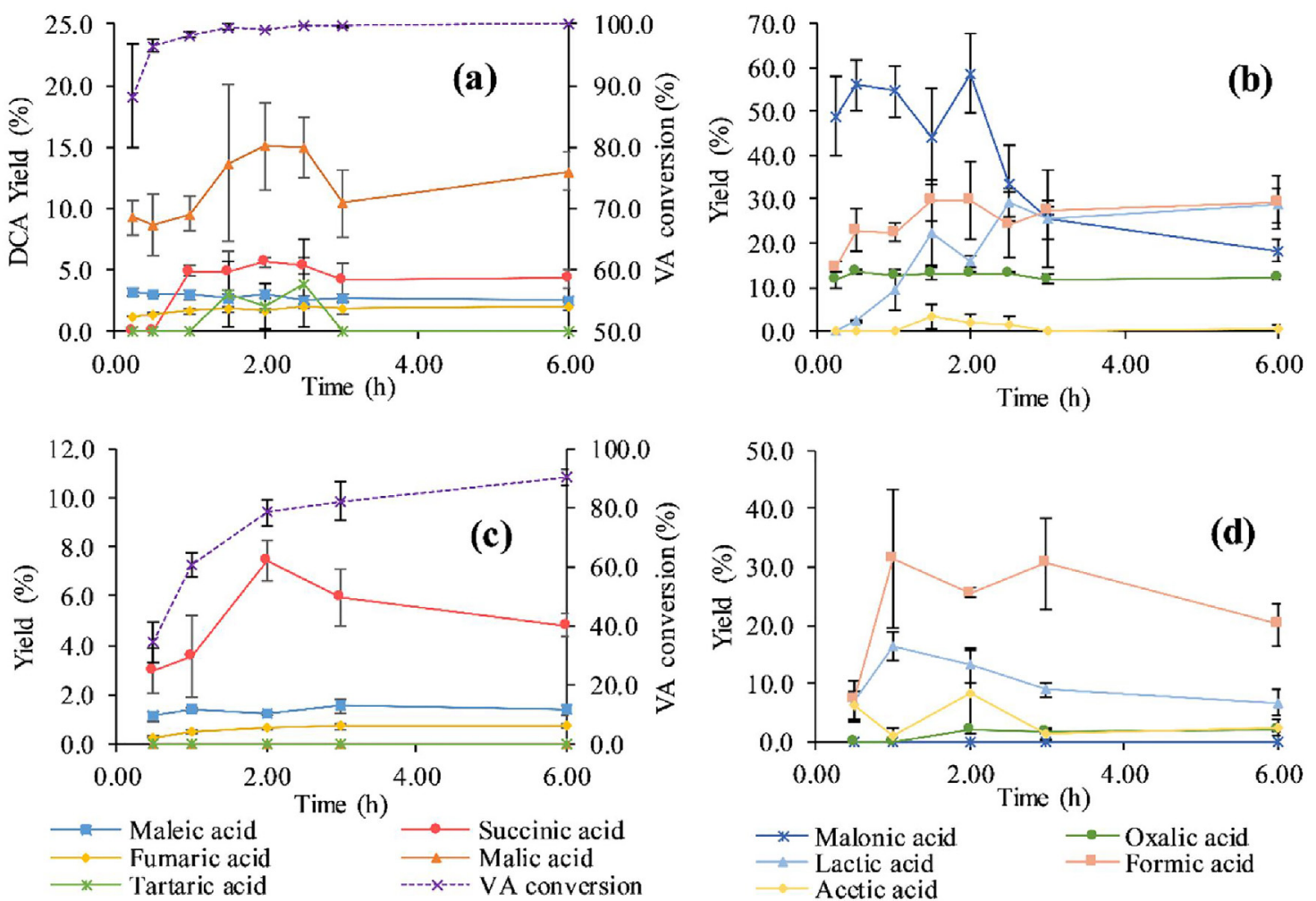

Fig. 4 - Effect of time in vanillic acid (VA) oxidation. (a) $C_{4}$ dicarboxylic acid ( $C_{4}$-DCA) yield, VA conversion and (b) degradation products yield at $\mathrm{pH} 10.5$; (c) $\mathrm{C}_{4}$-DCA yield, VA conversion and (d) degradation products yield at $\mathrm{pH} 4.0$. (All reactions at $\left.145^{\circ} \mathrm{C}\right)$.

Malonic acid, an intermediate product in the $\mathrm{C}_{4}$-DCA degradation process, decreased through time; while lactic, acetic and formic acids, also degradation products according to Fig. 3, increased their concentration until $3 \mathrm{~h}$, but then decreased, confirming the degradation of the $\mathrm{C}_{4}$-DCA (Fig. $4 \mathrm{~b}$ ). This observation indicates that $\mathrm{H}_{2} \mathrm{O}_{2}$ is highly reactive at alkaline $\mathrm{pH}$ and high temperatures. After prolonged reaction times, an overoxidation of the already produced $\mathrm{C}_{4}$-DCA occurs, originating low-molecular weight degradation products, like malonic, oxalic, lactic, acetic and formic acids. Therefore, the oxidation reaction should be performed at short times to avoid the loss of $\mathrm{C}_{4}$-DCA products. Also, the high nucleophilic capacity of $\mathrm{H}_{2} \mathrm{O}_{2}$ at alkaline $\mathrm{pH}$ causes the hydroxylation of double bonds, in both maleic and fumaric acids, leading to the formation of malic and tartaric acids, but avoiding the production of succinic acid at higher yields. In this work, succinic acid was identified (up to $5.6 \mathrm{~mol} \%$ ), while Su et al. (2014) that reported guaiacol alkaline peroxide oxidation with TS- 1 at $80^{\circ} \mathrm{C}$ shown no production of succinic acid, but higher maleic acid yield (up to $27.7 \mathrm{~mol} \%$ ). Looking to achieve high yields for succinic acid, as according to step c) in Fig. 3, a source of $\mathrm{H}^{+}$should be included, which is not the case of alkaline oxidation.

According to Fig. 3, vanillic acid is firstly oxidised to oand $p$-quinones, which react with free radicals to produce ring-opening reactions, obtaining maleic acid. Maleic acid is isomerised to fumaric acid if heated at $120^{\circ} \mathrm{C}$ in aqueous solution (Whelan, 1994), producing malic acid at higher temperatures (Gao et al., 2018). This observation indicates that during the transition of maleic to fumaric acid, the double bond is more labile to be hydroxylated, explaining why at higher temperatures malic and tartaric acids were present at higher amounts, especially after several minutes of reaction. The hydroxylated acids were at lower amounts (max.
$2.9 \mathrm{~mol} \%$ ) in Su et al. (2014) work, which used lower temperatures.

At acidic $\mathrm{pH}(\mathrm{pH}=4.0)$, VA conversion was slower comparatively with alkaline medium (Fig. 4c). The $\mathrm{H}_{2} \mathrm{O}_{2}$ reactivity at alkaline $\mathrm{pH}$ is higher than in acidic $\mathrm{pH}$, since, for $\mathrm{pH}>9$, dissociation to hydroperoxide anions occurs (Yin et al., 2015). This behaviour remains even when the TS-1 catalyst is used, a fact related to the inferior reactivity of $\mathrm{H}_{2} \mathrm{O}_{2}$ in acidic $\mathrm{pH}$ (Xiang and Lee, 2000).

The abundance of $\mathrm{C}_{4}$-DCA production under acid conditions was different from alkaline $\mathrm{pH}$, as can be seen in Fig. 4c; the more abundant acid was succinic $(7.4 \mathrm{~mol} \%)$, accompanied by small quantities of maleic and fumaric acids. Malic and tartaric acids were not detected after $6 \mathrm{~h}$ of reaction. As seen in Fig. 3, when acidic pH is selected, the already produced maleic/fumaric acids avoid the hydroxylation reaction towards malic/tartaric acids. Still, the $\mathrm{H}^{+}$source promotes saturation of the double bonds to produce succinic acid at higher selectivity. Previous publications (Bi et al., 2017; Cronin et al., 2017; Ma et al., 2014) show that succinic acid can be obtained from lignin and lignin model compounds (guaiacol, catechol, vanillin) using peroxide oxidation under acidic $\mathrm{pH}$ in the presence of different catalysts. Nevertheless, none of the cited works used TS-1 catalyst in acidic medium to obtain succinic acid. In this work, the highest succinic acid yield was achieved after $2.0 \mathrm{~h}$ reaction at $145^{\circ} \mathrm{C}(7.4 \mathrm{~mol} \% ; 5.2 \mathrm{wt} \%)$, similarly to the ones reported by $\mathrm{Ma}$ et al. (2014), using $\mathrm{FeCuS}_{2}$ catalyst to oxidise guaiacol (5.4 wt\%) and catechol (4.5 wt\%).

Under acidic conditions, lower levels of degradation products were obtained, comparatively with alkaline conditions (Fig. 4d). Lactic and formic acids concentration did not increase through reaction time, as it happened in alkaline oxidation. These facts show that the level of oxidation was weaker in this 


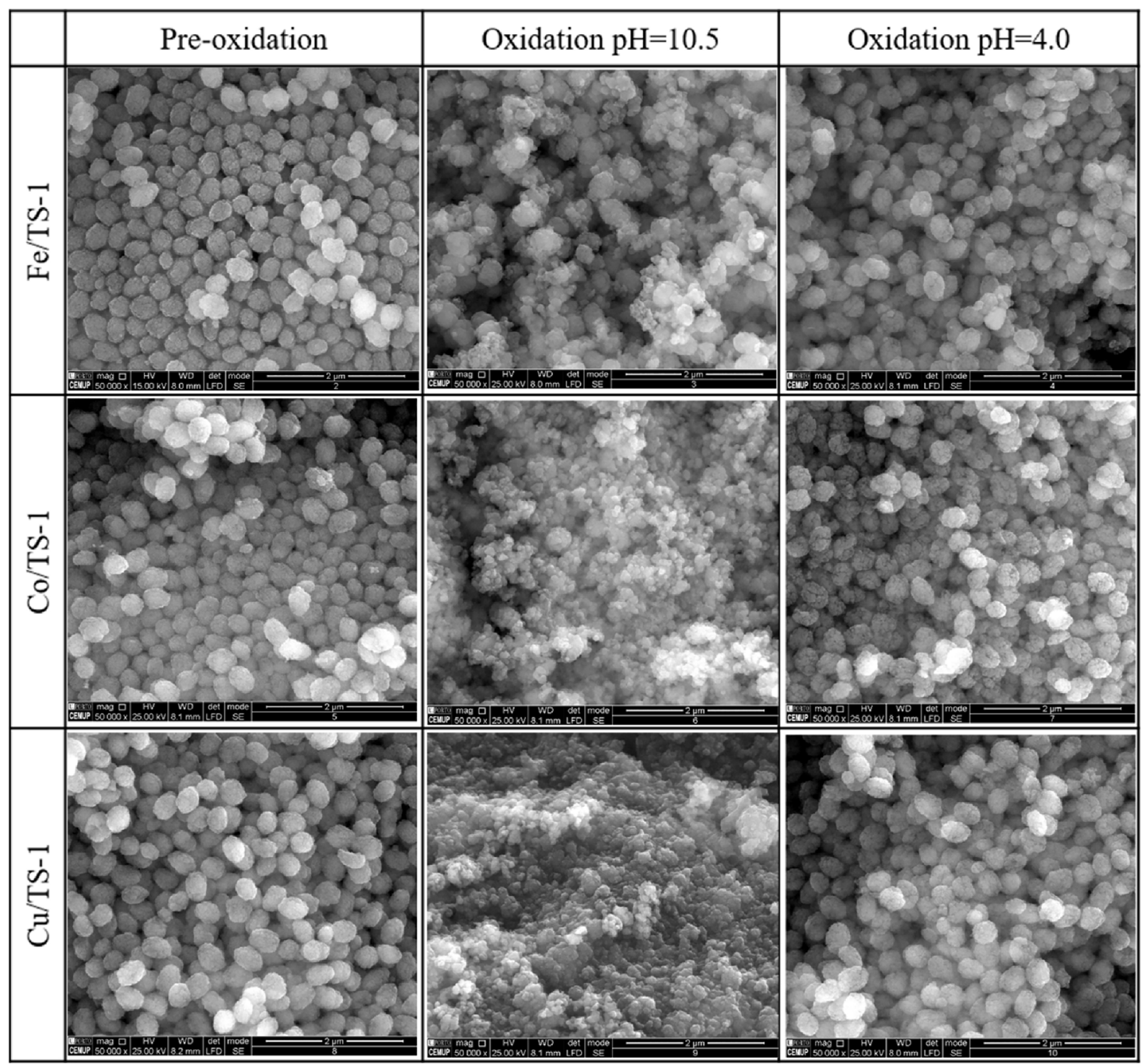

Fig. 5 - SEM images from modified TS-1 catalysts $(50,000 x)$.

Table 1 - Transition metal-modified TS-1 catalyst's physical properties.

\begin{tabular}{llllllll} 
Reaction condition & \multicolumn{3}{c}{ Ti/Si ratio $^{\mathrm{a}}$} & & \multicolumn{3}{c}{ Crystallinity (\%) $^{\mathrm{b}}$} \\
\cline { 2 - 3 } & Cu/TS-1 & Co/TS-1 & Fe/TS-1 & & Cu/TS-1 & Co/TS-1 & Fe/TS-1 \\
\hline After modification & 0.024 & 0.019 & 0.026 & 100 & 91 & 100 \\
pH 10.5 & 0.032 & 0.034 & 0.026 & 60 & 27 & 46 \\
pH 4.0 & 0.023 & 0.019 & 0.024 & 100 & 97 & 91 \\
\hline
\end{tabular}

${ }^{a}$ Non-modified TS-1 Ti/Si ratio: 0.023.

b Based on peak intensity at $2 \Theta=23.04^{\circ}$. TS- 1 non-modified catalyst $=100 \%$ crystallinity.

case, being the produced $\mathrm{C}_{4}$-DCA better preserved, avoiding the extensive degradation observed in the alkaline oxidation. Therefore, according to the desired $\mathrm{C}_{4}$-DCA, different $\mathrm{pH}$ conditions should be selected. If succinic acid is the target, VA oxidation should be performed at acidic medium to avoid maleic/fumaric acids oxidation to their hydroxylated derivatives.

\subsection{Oxidation with modified TS-1 catalyst}

3.2.1. Catalyst modification with transition metal oxides Transition metals, like $\mathrm{Co}, \mathrm{Fe}, \mathrm{Cu}, \mathrm{Mn}$ and $\mathrm{Ni}$, have been widely studied because of their capability to activate the peroxide oxidation; as homogeneous (soluble salts) or heterogeneous (metal oxides, supported metal oxides, or as part of compounds, such as $\mathrm{CuFeS}_{2}$ ) catalysts (Leary and Schmidt, 2010;
Ma et al., 2014; Sun et al., 1999; Vangeel et al., 2018; Védrine, 2017; Zeng et al., 2015). These metals can enhance the production of free reactive radicals, converting VA to quinones, but also causing ring-opening reactions, producing DCA (Bi et al., 2017). They can increase $\mathrm{H}_{2} \mathrm{O}_{2}$ reactivity, which is important at acidic $\mathrm{pH}$, like in Fenton's reaction, which uses $\mathrm{Fe}^{2+} / \mathrm{Fe}^{3+}$ ion pair as a catalyst with a reactivity peak at $\mathrm{pH}=2.8-3.0$ (Wang et al., 2012).

A 2 wt $\%$ metallic oxide loading was selected based on the work of Widiarti et al. (2012), which reported that higher loads would cover the TS-1 surface, blocking the access to the pores. If this blockage occurs, the $\mathrm{H}_{2} \mathrm{O}_{2}$ will not access $\mathrm{Ti}^{4+}$ sites to release the $\mathrm{HO}^{\circ}$ and $\mathrm{HO}_{2}{ }^{-}$radicals, decreasing the activity of the modified catalyst, and enhancing $\mathrm{H}_{2} \mathrm{O}_{2}$ dismutation to $\mathrm{H}_{2} \mathrm{O}$ and $\mathrm{O}_{2}$. This behaviour was previously observed with $\mathrm{Cu} / \mathrm{TS}-$ 1 (Widiarti et al., 2012) and Fe/TS-1 (Prasetyoko et al., 2010) 

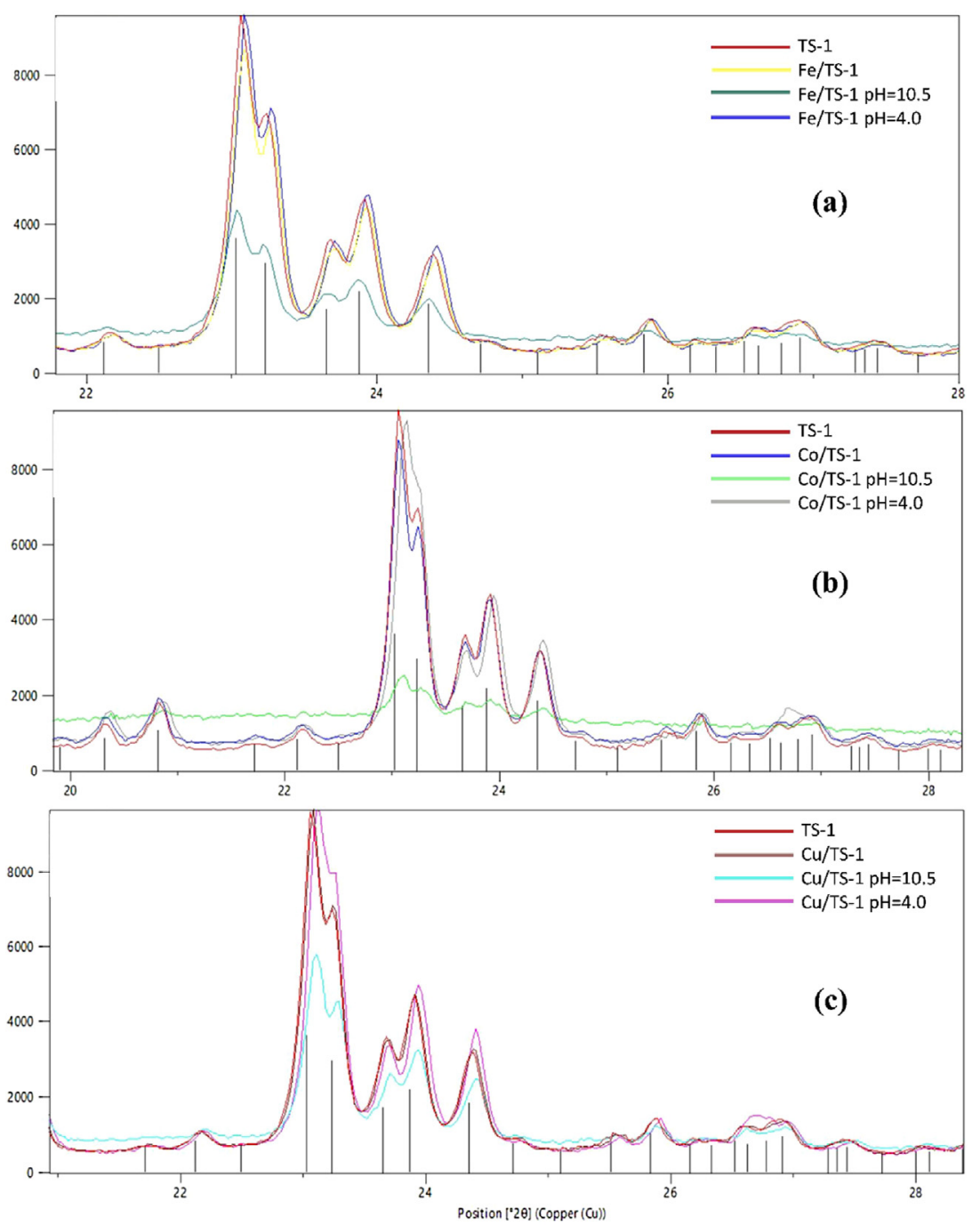

Fig. 6 - XRD Diffractograms for modified TS-1 catalysts: (a) Fe/TS-1; (b) Co/TS-1; (c) Cu/TS-1. Each figure includes the modified non-used catalyst, the catalyst used under acidic and alkaline conditions, and the original TS-1 diffractogram as comparison.

catalysts. In this work, modifications with $\mathrm{Cu}$, Co and Fe have been chosen.

As seen in the SEM images (Fig. 5, Pre-oxidation), all modified catalysts presented no metal oxide crystals visible on the particle's surface. XRD results (Fig. 6) showed that the MFI structure was not affected after impregnation with the metal, namely the characteristic diffraction lines of TS$1(2 \Theta=23.04,23.23,23.65,23.88,24.36)$ were present, at the same peak height, in all modified catalysts. Crystallinity percentage, after modification with the selected metals, did not change (Table 1). No diffraction lines were assigned to the metal oxides in the modified catalysts, due to their low percentage in the matrix. The Ti/Si ratio of the original catalyst $(\mathrm{Ti} / \mathrm{Si}$ ratio $=0.023)$ was kept after the metal impregnation, as reported in Table 1.

\subsection{2. $C_{4}$-DCA production under alkaline and acidic conditions}

To compare the effect of the catalyst modification with metallic ions, reactions were done at $145^{\circ} \mathrm{C}$ for $2 \mathrm{~h}$, which was the time and temperature where the highest yield for succinic acid was obtained. At alkaline conditions, all the modified catalysts give rise to complete VA conversion, but the production yield of the targeted $\mathrm{C}_{4}$-DCA was not improved (Fig. 7a). Only maleic and fumaric acids were produced at similar yields, comparatively with the non-modified TS- 1 catalyst, and tartaric acid was not detected. A prominent bubbling was observed when the Co/TS- 1 and $\mathrm{Cu} / \mathrm{TS}-1$ catalyst were added to the reaction medium, indicating that $\mathrm{H}_{2} \mathrm{O}_{2}$ is quickly degraded to $\mathrm{O}_{2}$, skipping the release of the active radicals needed to the ringopening reactions. Since TS- 1 can only activate $\mathrm{H}_{2} \mathrm{O}_{2}$ and not $\mathrm{O}_{2}$ (Přech, 2018), lower productivity is expected when $\mathrm{H}_{2} \mathrm{O}_{2}$ is degraded to $\mathrm{O}_{2}$. All these oxidations produced dark-coloured solutions, and organic sediments in the Co/TS-1 reaction, which may be derived from VA oxidised derivatives condensation reactions. The condensation reactions gave rise to higher molecular-weight compounds, which was confirmed by GPC analyses (Fig. 8). Lower over-oxidation occurred, because lower degradation products yields were obtained (Fig. 7c,e), confirming that modified catalysts enhanced oxidant degradation instead of promoting the oxidation of VA into $\mathrm{C}_{4}$-DCA.

Under acidic conditions, VA conversion was improved when using $\mathrm{Cu} / \mathrm{TS}-1$ and $\mathrm{Fe} / \mathrm{TS}-1$, achieving complete conversion after $2 \mathrm{~h}$ at $145^{\circ} \mathrm{C}$. With Co/TS-1 catalyst, only $57 \%$ conversion was achieved, while for TS-1 non-modified catalyst $78 \%$ conversion was reached. The higher activity for $\mathrm{Cu} / \mathrm{TS}-$ 1 catalyst was expected due to the intermediate reduction potential of $\mathrm{Cu}^{2+}$ (Schutyser et al., 2018), which is confirmed by the higher formic acid production, a degradation prod- 

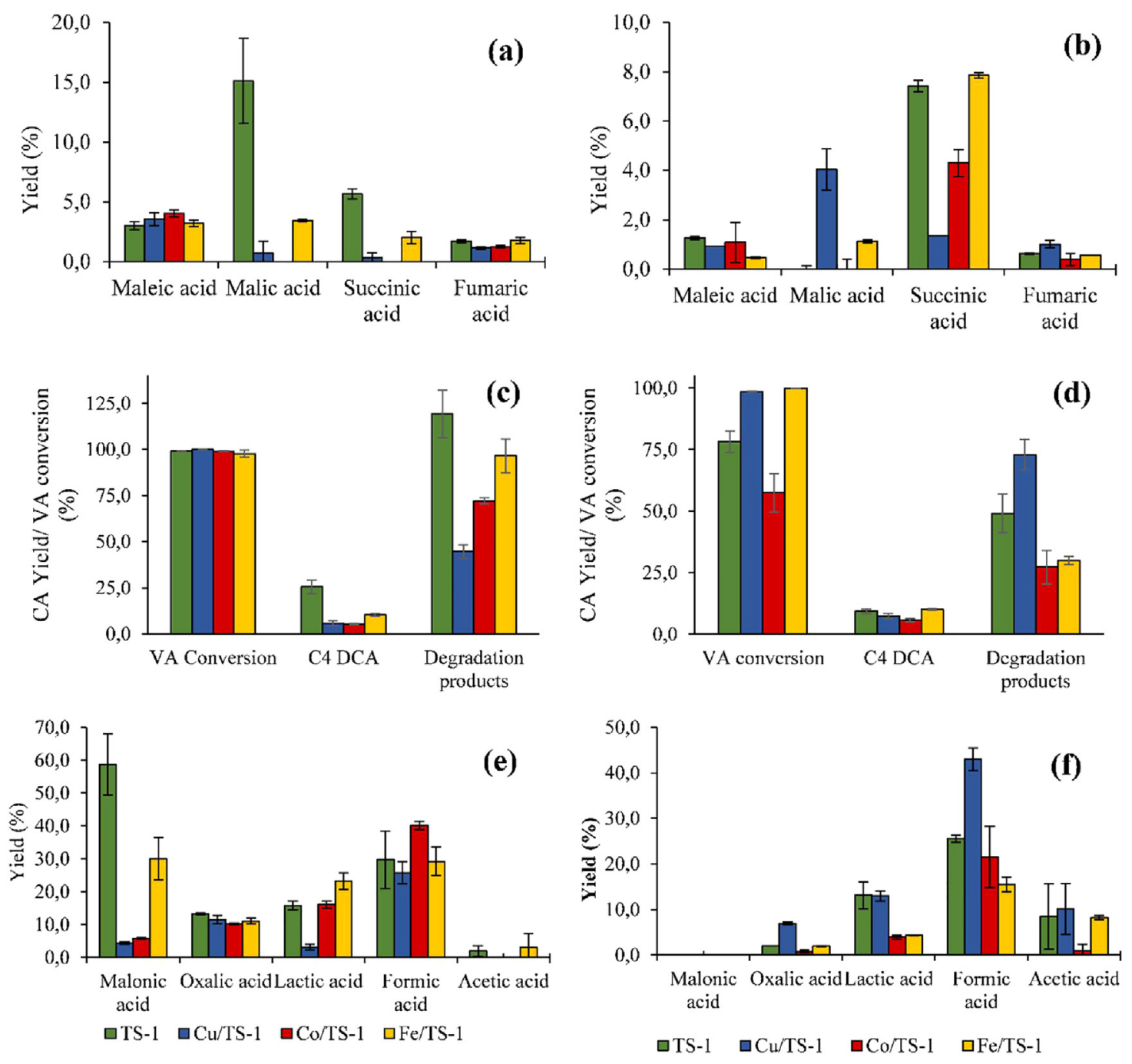

Fig. 7 - Yields achieved with modified catalysts, and comparison with non-modified catalyst, under different pHs. $\mathrm{C}_{4}$-DCA yields at (a) $\mathrm{pH}=10.5$ and (b) $\mathrm{pH}=4.0$; VA conversion and acid yields at (c) $\mathrm{pH}=10.5$ and (d) $\mathrm{pH}=4.0$; Degradation products at (e) $\mathrm{pH}=10.5$ and $(\mathrm{f}) \mathrm{pH}=4.0\left(145^{\circ} \mathrm{C}, 2.0 \mathrm{~h}\right)$.
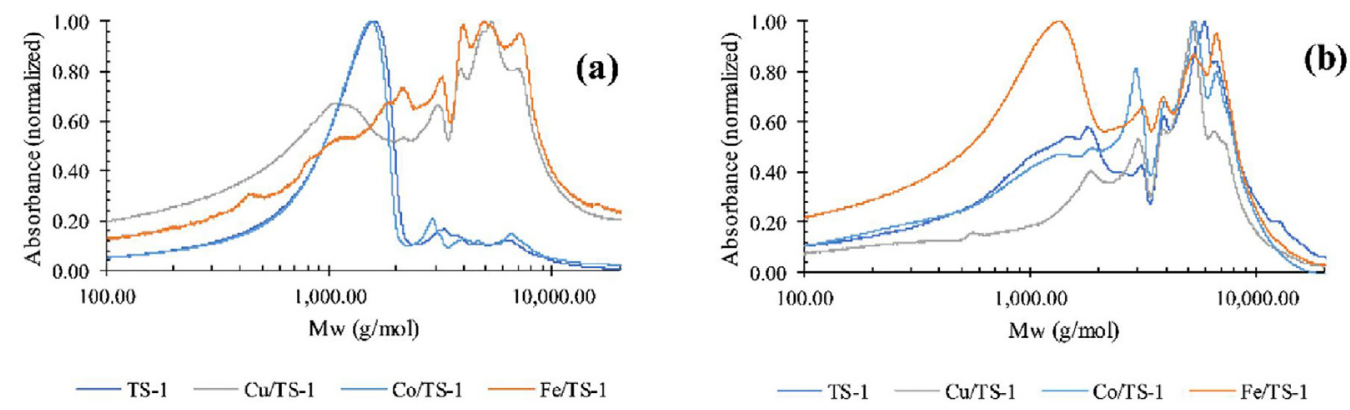

(b)

Fig. 8 - GPC analysis for vanillic acid oxidation using modified TS-1 catalysts, under different pH. Vanillic acid oxidation with non-modified TS-1 GPC curve is shown as a comparison for each curve. (a) pH 4.0, (b) pH 10.5. (Reaction conditions $\left.145^{\circ} \mathrm{C}, 2.0 \mathrm{~h}\right)$.

uct of VA oxidation (Fig. 7f). A higher amount of malic acid was also observed, suggesting the conversion of the original maleic/fumaric acids into this compound, avoiding the conversion to succinic acid, even at acidic $\mathrm{pH}$. Fe/TS-1 improved VA oxidation due to iron capacity to act as a Fenton's catalyst, enhancing $\mathrm{HO}^{\circ}$ and $\mathrm{HO}_{2}{ }^{\circ}$ radicals formation through the mixture of $\mathrm{Fe}^{2+} / \mathrm{Fe}^{3+}$ ions (Wang et al., 2012). Malic acid was also produced with Fe/TS-1 and Cu/TS-1 catalysts (Fig. 7b), suggesting that this oxidation was stronger than the one with non-modified TS-1.
The Fe/TS- 1 catalyst was the only modified catalyst form providing a high yield of succinic acid $(7.9 \mathrm{~mol} \%)$; slightly higher than with the non-modified TS-1. Moreover, lower amounts of degradation products were detected, showing that oxidation was more selective. Iron has been reported as the less reactive of the three tested metals (Schutyser et al., 2018). This lower reactivity lowers $\mathrm{H}_{2} \mathrm{O}_{2}$ degradation but generating the needed radicals to open the aromatic ring. However, the appearance of malic acid, which was not present in the non-modified TS-1 experiment, shows that even with lower 
reactivity, Fe catalyst produces more free radicals than the non-modified TS-1 catalyst. Under acidic oxidation, higher molecular weight compounds were produced mainly when Fe and $\mathrm{Cu}$ catalysts were used, but at lower amounts, in comparison to alkaline oxidation (Fig. 8b). Moreover, no organic sediments nor coloured solutions were observed under this $\mathrm{pH}$ condition.

\subsubsection{Effect of reaction conditions in the modified catalysts} The modified catalysts suffered degradation after alkaline oxidation (Fig. 5), resulting in particles with smaller diameters and loss of organisation. EDS analysis showed that the Ti/Si ratio was higher after alkaline oxidation (Table 1), suggesting that the internal zeolite structure was affected, and $\mathrm{Si}$ atoms were leached out from the catalyst structure. XRD results showed that alkaline oxidation leads to significant MFI crystallinity losses. This effect can be observed as a decrease in the intensity of the TS- 1 characteristic peaks (Fig. 6), thus a reduction of crystallinity percentage (Table 1). The higher crystallinity loss was observed for the Co/TS-1 catalyst. Titanosilicates zeolites, including TS-1, are reported as resistant to concentrated mineral acids, but not to alkaline pHs due to desilication development (Přech, 2018). To avoid catalyst degradation, the recommended $\mathrm{NaOH}$ concentration should be lower than $0.2 \mathrm{~mol} / \mathrm{L}$, since higher levels can cause total disruption of the framework (Přech, 2018).

After acidic oxidation, the catalyst particles did not show any structural changes (Fig. 5), and XRD results confirmed that crystallinity was maintained (Table 1), pointing out that acidic environment is safer for TS-1 catalyst structure.

To check leaching of metallic ions, in acidic or alkaline environment, soluble ions were quantified by atomic absorption analysis. Fe/TS-1 catalyst showed no leaching, while Co/TS-1 and $\mathrm{Cu} / \mathrm{TS}-1$ showed leaching in acidic $\mathrm{pH}(5 \mathrm{mg} / \mathrm{L}$ and $13 \mathrm{mg} / \mathrm{L}$, respectively), and $\mathrm{Cu} / \mathrm{TS}-1$ leaching at alkaline $\mathrm{pH}(5 \mathrm{mg} / \mathrm{L})$. $\mathrm{CuO}$ has the lowest solubility in alkaline medium ( $\mathrm{pH}$ around $8-9)$ at $145^{\circ} \mathrm{C}$, and high solubility in both acidic and alkaline $\mathrm{pH}$, explaining the observed leaching (Palmer, 2005). Therefore, Co/TS-1 and Cu/TS-1 catalysts did not lead to enhance DCA yield, and showed low chemical stability, due to leachate of metals, disabling their possible use until no procedure to avoid leaching could be carried out. Only Fe/TS-1 showed to be a stable catalyst, in both media. Stability increase could be achieved if different metal salts, selected among the ones that have been proven to be insoluble in alkaline or acidic $\mathrm{pH}$, are chosen, which should be done individually according to each metallic ion. It is not recommended to increase calcination temperature, due to possible sintering of the TS-1 catalyst.

\section{Conclusions}

The use of TS-1 catalyst in the catalytic wet peroxide oxidation of VA enhanced the production of $\mathrm{C}_{4}$-DCA, comparatively with the non-catalysed reaction. The type of produced acids depends mainly on the used temperature, $\mathrm{pH}$ and reaction time. An alkaline medium caused an over-oxidation of VA, giving rise to hydroxylated acids, like malic and tartaric, together with high degradation levels. In acidic $\mathrm{pH}$, the main produced acid was succinic, and a lower amount of degradation products was observed. Therefore, VA oxidation acted similarly to other lignin model compounds, where the oxidation of the aromatic ring is the first step, getting open to produce $\mathrm{C}_{4}$-DCA. However, these $\mathrm{C}_{4}$-DCA can quickly degrade to low-molecular weight compounds, especially under alkaline conditions and long reaction times. If succinic acid is the target compound, acidic oxidation should be selected.

When TS- 1 catalyst is modified with $\mathrm{Fe}$, $\mathrm{Co}$ and $\mathrm{Cu}$ oxides, the productivity of $\mathrm{C}_{4}$-DCA was not improved under alkaline $\mathrm{pH}$, due to the high degradation of $\mathrm{H}_{2} \mathrm{O}_{2}$ to $\mathrm{O}_{2}$, associated mainly with $\mathrm{Co}$ and $\mathrm{Cu}$ oxides. In acidic $\mathrm{pH}, \mathrm{Fe} / \mathrm{TS}-1$ and $\mathrm{Co} / \mathrm{TS}-$ 1 catalysts increased VA conversion and oxidative reaction, but only Fe/TS-1 showed a slight improvement in succinic acid production and stability against leaching. Leaching in $\mathrm{Cu}$ and Co catalysts was observed, and their use is not recommended. Under alkaline oxidation, modified TS-1 catalysts suffered desilication and loss of external structure, but not in acid conditions. Thus, it is recommended carrying out oxidations with TS-1 catalyst at acidic or neutral $\mathrm{pH}$.

\section{Conflict of interest}

The authors declare no competing financial interest.

\section{Author contributions}

The manuscript was written through the contributions of all authors. All authors have given approval to the final version of the manuscript. All authors contributed equally.

\section{Acknowledgements}

The authors gratefully acknowledge support from Fundação para a Ciência e a Tecnologia (FCT), Portugal, Grant numbers: UID/EQU/50020/2019, UID/AGR/00690/2019; European Cooperation in Science and Technology, Grant numbers: LignoCOST (CA17128) and Costa Rican Science, Technology and Telecommunications Ministry, Costa Rica. Scholarship number: MICITT-PINN-CON-2-1-4-17-1-002.

\section{References}

Abdelaziz, O.Y., Li, K., Tunå, P., Hulteberg, C.P., 2018. Continuous catalytic depolymerisation and conversion of industrial kraft lignin into low-molecular-weight aromatics. Biomass Convers. Biorefinery 8, 455-470, http://dx.doi.org/10.1007/s13399-017-0294-2.

Bi, Z., Li, Z., Yan, L., 2017. Catalytic oxidation of lignin to dicarboxylic acid over the CuFeS2 nanoparticle catalyst. Green Process. Synth., http://dx.doi.org/10.1515/gps-2017-0056.

Cheng, C., Wang, J., Shen, D., Xue, J., Guan, S., Gu, S., Luo, K.H., 2017. Catalytic oxidation of lignin in solvent systems for production of renewable chemicals: a review. Polymers (Basel) 9, 38-50, http://dx.doi.org/10.3390/polym9060240.

Clerici, M.G., 2015. The activity of titanium silicalite-1 (TS-1): some considerations on its origin. Kinet. Catal. 56, 453-458, http://dx.doi.org/10.7868/s045388111504005x.

Costa, C.A.E., Pinto, P.C.R., Rodrigues, A.E., 2018. Lignin fractionation from $\mathrm{E}$. Globulus kraft liquor by ultrafiltration in a three stage membrane sequence. Sep. Purif. Technol. 192, 140-151, http://dx.doi.org/10.1016/j.seppur.2017.09.066.

Cronin, D.J., Zhang, X., Bartley, J., Doherty, W.O.S., 2017. Lignin depolymerisation to dicarboxylic acids with sodium percarbonate. ACS Sustain. Chem. Eng. 5, 6253-6260, http://dx.doi.org/10.1021/acssuschemeng.7b01208.

Erdocia, X., Ruiz, E., Romero, I., Diaz, M.J., Castro, E., Labidi, J., 2017. Lignin characterisation from two different pretreatments in bioethanol production processes from olive tree pruning. Chem. Eng. Trans. 61, 421-426, http://dx.doi.org/10.3303/CET1761068.

Gao, Z., Chen, W., Chen, X., Wang, D., Yi, S., 2018. Study on the isomerisation of maleic acid to fumaric acid without catalyst. 
Bull. Korean Chem. Soc. 39, 920-924,

http://dx.doi.org/10.1002/bkcs.11499.

Hasegawa, I., Inoue, Y., Muranaka, Y., Yasukawa, T., Mae, K., 2011. Selective production of organic acids and depolymerisation of lignin by hydrothermal oxidation with diluted hydrogen peroxide. Energy Fuels 25, 791-796, http://dx.doi.org/10.1021/ef101477d.

Höfer, R., 2015. Sugar- and starch-based biorefineries. In: Industrial Biorefineries White Biotechnology. Elsevier, pp. 157-235,

http://dx.doi.org/10.1016/B978-0-444-63453-5.00005-7.

Kamm, B., Gruber, P.R., Kamm, M., 2008. Biorefineries-Industrial Processes and Products: Status Quo and Future Directions., http://dx.doi.org/10.1002/9783527619849.

Kang, J., Irmak, S., Wilkins, M., 2019. Conversion of lignin into renewable carboxylic acid compounds by advanced oxidation processes. Renew. Energy 135, 951-962, http://dx.doi.org/10.1016/j.renene.2018.12.076.

Kang, S., Li, X., Fan, J., Chang, J., 2013. Hydrothermal conversion of lignin: a review. Renew. Sustain. Energy Rev. 27, 546-558, http://dx.doi.org/10.1016/j.rser.2013.07.013.

Leary, G., Schmidt, J.A., 2010. The chemistry of lignin-retaining bleaching: oxidative bleaching agents. In: Heitner, C., Dimmel, D.R., Schmidt, J.A. (Eds.), Lignins and Lignans: Advances in Chemistry. CRC Press, Boca Raton, pp. 439-469, http://dx.doi.org/10.1201/EBK1574444865-c12.

Li, C., Zhao, X., Wang, A., Huber, G.W., Zhang, T., 2015. Catalytic transformation of lignin for the production of chemicals and fuels. Chem. Rev. 115, 11559-11624, http://dx.doi.org/10.1021/acs.chemrev.5b00155.

Ma, R., Guo, M., Zhang, X., 2014. Selective conversion of biorefinery lignin into dicarboxylic acids. ChemSusChem 7, 412-415, http://dx.doi.org/10.1002/cssc. 201300964.

Ma, R., Xu, Y., Zhang, X., 2015. Catalytic oxidation of biorefinery lignin to value-added chemicals to support sustainable biofuel production. ChemSusChem 8, 24-51, http://dx.doi.org/10.1002/cssc.201402503.

Palmer, A., 2005. Solubility of copper oxides in water and steam. 14Th Int. Conf. Prop. Water Steam Kyoto.

Pandey, M.P., Kim, C.S., 2011. Lignin depolymerisation and conversion: a review of thermochemical methods. Chem. Eng. Technol. 34, 29-41, http://dx.doi.org/10.1002/ceat.201000270.

Prasetyoko, D., Royani, C.E., Fansuri, H., Ramli, Z., Nur, H., 2010. Catalytic performances of Fe2O3/TS-1 catalyst in phenol hydroxylation reaction. Indones. J. Chem. 10, 149-155.

Přech, J., 2018. Catalytic performance of advanced titanosilicate selective oxidation catalysts - a review. Catal. Rev. - Sci. Eng. 60, 71-131, http://dx.doi.org/10.1080/01614940.2017.1389111.

Rodrigues, A.E., Pinto, P.C., de, O.R., Barreiro, M.F., Esteves da Costa, C.A., Ferreira da Mota, M.I., Fernandes, I., 2018. An integrated approach for added-value products from lignocellulosic biorefineries. Springer International Publishing. Cham,

http://dx.doi.org/10.1007/978-3-319-99313-3.
Schutyser, W., Kruger, J.S., Robinson, A.M., Katahira, R., Brandner, D.G., Cleveland, N.S., Mittal, A., Peterson, D.J., Meilan, R., Román-Leshkov, Y., Beckham, G.T., 2018. Revisiting alkaline aerobic lignin oxidation. Green Chem. 20, 3828-3844, http://dx.doi.org/10.1039/C8GC00502H.

Su, J., Yang, L., Liu, R.N., Lin, H., 2014. Low-temperature oxidation of guaiacol to maleic acid over TS-1 catalyst in alkaline aqueous $\mathrm{H} 2 \mathrm{O} 2$ solutions. Chin. J. Catal. 35, 622-630, http://dx.doi.org/10.1016/S1872-2067(14)60039-5.

Sun, Y., Fenster, M., Yu, A., Berry, R.M., Argyropoulos, D.S., 1999. The effect of metal ions on the reaction of hydrogen peroxide with Kraft lignin model compounds. Can. J. Chem. 77, 667-675, http://dx.doi.org/10.1139/v99-036.

Vangeel, T., Schutyser, W., Renders, T., Sels, B.F., 2018. Perspective on lignin oxidation: advances, challenges, and future directions. Top. Curr. Chem. 376, 30, http://dx.doi.org/10.1007/s41061-018-0207-2.

Védrine, J., 2017. Heterogeneous catalysis on metal oxides. Catalysts 7, 341, http://dx.doi.org/10.3390/catal7110341.

Wang, C., Liu, H., Sun, Z., 2012. Heterogeneous photo-fenton reaction catalysed by nanosized iron oxides for water treatment. Int. J. Photoenergy 2012, 1-10, http://dx.doi.org/10.1155/2012/801694.

Werpy, T., Petersen, G., 2004. Top Value Added Chemicals from Biomass: Volume I - Results of Screening for Potential Candidates from Sugars and Synthesis Gas. U.S. Department of Energy, United States, http://dx.doi.org/10.2172/926125.

Whelan, A., 1994. Polymer Technology Dictionary, 1st ed. Springer Netherlands, http://dx.doi.org/10.1007/978-94-011-1292-5.

Widiarti, N., Ediati, R., Fansuri, H., Prasetyoko, D., 2012. Preparation, characterisation and catalytic activity of $\mathrm{CuO} / \mathrm{TS}-1$ on benzene hydroxylation reaction. MAKARA Sci. Ser. 15, 135-147, http://dx.doi.org/10.7454/mss.v15i2.1063.

Xia, C., Peng, X., Zhang, Y., Wang, B., Lin, M., Zhu, B., Luo, Y., Shu, X., 2017. Environmental-friendly catalytic oxidation processes based on hierarchical titanium silicate zeolites at SINOPEC. In: Karamé, I. (Ed.), Green Chemical Processing and Synthesis. InTech, pp. 119-150, http://dx.doi.org/10.5772/intechopen.68389.

Xiang, Q., Lee, Y.Y., 2000. Oxidative cracking of precipitated hardwood lignin by hydrogen peroxide. Appl. Biochem. Biotechnol. 84-86, 153-162, http://dx.doi.org/10.1385/ABAB:84-86:1-9:153.

$\mathrm{Xu}$, C., Arancon, R.A.D., Labidi, J., Luque, R., 2014. Lignin depolymerisation strategies: towards valuable chemicals and fuels. Chem. Soc. Rev. 43, 7485-7500, http://dx.doi.org/10.1039/c4cs00235k.

Yin, G., Jin, F., Yao, G., Jing, Z., 2015. Hydrothermal conversion of catechol into four-carbon dicarboxylic acids. Ind. Eng. Chem. Res. 54, 68-75, http://dx.doi.org/10.1021/ie5036447.

Zeng, J., Yoo, C.G., Wang, F., Pan, X., Vermerris, W., Tong, Z., 2015. Biomimetic fenton-catalyzed lignin depolymerisation to high-value aromatics and dicarboxylic acids. ChemSusChem 8, 861-871, http://dx.doi.org/10.1002/cssc.201403128. 